\title{
ANALISIS PENGARUH PERANG, KEMISKINAN DAN DISKRIMINASI TERHADAP PEREMPUAN DAN ANAK DALAM KONTEKS PERDAGANGAN MANUSIA
}

\author{
Yusnarida Eka Nizmi \\ Hubungan Internasional, Universitas Riau \\ Email: eka.nizmi@lecturer.unri.ac.id
}

\begin{abstract}
This study aims to describe the unhappiness of being women and children since human trafficking crimes dissapear their lives that driven by war, poverty and discrimination. There are various casualities that trigger human trafficking and the involvement of trafficker in this humanity crime. This study reviews various literatures since library research is the method of this research. This research analyzes the concept of war, poverty, and domestic conflict. Women and children become vulnerable target to be smuggled illegally to destination countries. Many of them finally end up in torture, violance and sexual exploitation. They have to keep working with minimum salary just for paying transportation cost. For smugglers, these vulnerable people are potential target to get money from selling them to other person or group. The smugglers lied to them about the truly motives and for the victims, the cost and exploitation are the consequences to reveal all their the horrible conditions. This research shows that how women and children start their sad journey since devastated and insecure in the neighbourhood because of war, domestic conflict and never ending poverty
\end{abstract}

Keywords: Human Trafficking, War, Poverty, Discrimination, Women and Children

\section{PENDAHULUAN}

Para pelaku perdagangan orang menargetkan mereka yang miskin, minim bantuan, perempuan-perempuan single di negara-negara miskin, negara-negara yang terlibat perang, atau bahkan negara-negara yang lagi ditimpa bencana. Para pelaku perdagangan orang membuat janji-janji palsu kepada para perempuan mengenai kehidupan indah di Eropa Barat, Amerika Serikat, Kanada, Israel, Australia, atau Jepang. Bagi banyak perempuan, tawaran ini seperti sebuah undian. Alih-alih mendapat surga seperti yang diimpikan, mereka justru berhadapan dengan kelompok kejahatan terorganisir yang menyiksa lahir batin mereka. Dalam semua studi yang mengkaji perdagangan orang, para pelaku perdagangan orang menjanjikan perempuan-perempuan tersebut dengan upah yang tinggi dan kondisi kerja yang menyenangkan di negara-negara asing yang ditawarkan kepada mereka.

Mereka menjanjikan pada perempuan-perempuan yang menjadi korban perdagangan mengenai kota-kota besar yang menyenangkan seperti Tokyo, Sydney, London, Paris, Frankfurt, Munich, New York, Chicago, Los Angeles, Atlanta, Milan, Roma, Amsterdam, Jenewa, dan negara -negara lain yang akan menjadi kota-kota tujuan. Bagi para korban, cerita mengenai kota-kota tersebut seperti mimpi yang jadi kenyataan. Para korban ini adalah mereka yang mencoba lari dari tidak adanya harapan kehidupan di negara asal mereka. Para 
pelaku perdagangan orang pergi ke kota-kota, daerah pedesaan dan kota-kota kecil untuk merekrut para korban. Jenis pekerjaan yang mereka janjikan kepada para perempuan ini adalah sebagai pramusaji bartender pengasuh, model, pembantu rumah tangga, pekerja di salon, dan sebagainya.

Perdagangan perempuan dan anak adalah sebuah fenomena global. Ini merupakan kejahatan terhadap kemanusiaan. Perdagangan orang merupakan cerminan dari ketiadaan moral dan hilangnya prilaku yang baik. Banyak negara, khususnya negara-negara berkembang, sangat lambat dalam merespon keadaan perdagangan perempuan dan anak. Banyak organisasi-organisasi keagamaan dan NGO yang bersuara di berbagai negara sejak tahun 1970an terkait isu perdagangan orang. Namun suara-suara mereka tidak terlalu di dengar sampai munculnya protokol Palermo PBB pada tahun 2000, yang memberi ruang pada negara-negara untuk meratifikasi dengan jadwal deadline di 12 Desember 2002. protokol ini juga terbuka bagi semua negara untuk hadir menandatangani Protokol tersebut pada 12-15 Desember di Itali. Namun, ada beberapa negara tidak meratifikasi protokol tersebut sampai bulan September dan Oktober 2005. Penundaan itu menunjukkan bahawa beberapa negara belum merasa penting untuk merespon masalah perdagangan perempuan dan anak. Menyedihkan sekali mengetahui bahwa ini menandakan bahwa masih ada beberapa pihak yang mengabaikan rasa sakit yang diderita kaum perempuan.

\section{KERANGKA ANALISIS}

Tulisan ini menganalisis beberapa pemikiran terkait dengan Perang, konflik domestik, kemiskinan dan kejahatan. Elemen-elemen ini memberi ruang yang sangat besar untuk terciptanya transaksi perdagangan manusia. Merton dan Durkheim menyatakan bahwa konflik domestik dan perang yang terjadi di negara-negara miskin dan berkembang, memberi ruang pada konflik suku agar dapat mengontrol pemerintah, menjalankan praktik-praktik korupsi, kapitalisme, demokrasi yang berbasis kroni, menciptakan perpecahan sosial (Merton, 1968; Durkheim, 1964) di negara-negara tesebut. Dampak selanjutnya adalah, hancurnya penegakan hukum yang berperan sebagai mekanisme kontrol sosial (Hirschi, 1969).

Dalam rejim-rejim kolonial, konflik antar etnis dan sesama etnis, memunculkan adanya kediktatoran dan negara-negara predator. Seperti halnya rejim yang ada di Nigeria, Zaire, Uganda, Liberia, Bosnia- Herzegovina, Pecahan Yugoslavia, haiti, Myanmar, Pakistan, Sudan, Sri Lanka, Zimbabwe dan sebagianya. Polisi dalam konteks negara seperti ini, dimanfaatkan untuk melindungi agenda politik dari rezim yang diktator dan predator tersebut 
untuk memperluas kontrol pada kejahatan dan perlindungan bagi warga negara. Semakin besar angka populasi yang tidak memiliki pekerjaan, makan akan semakin banyak individu yang hidup tanpa harapan, hidup dalam bayang-bayang potensial perdagangan orang. Hasilnya adalah, pria-pria dan kelompok-kelompok yang ada dalam rejim terebut menemukan bagaimana para perempuan dan anak bertahan agar dapat selamat, menjadi target yang sangat mudah menjadi korban dari eksploitasi perdagangan. Kemiskikan bukanlah sebuah teori kejahatan yang universal. Dengan kata lain, kemiskinan tidak dapat menjelaskan kejahatan di semua budaya.

Namun, kemiskinan menjelaskan munculnya sejumlah kejahatan di negara berkembang, negara-negara industri, termasuk juga di dalam negara miskin. Thomas More (1949) menjelaskan, jika seorang pria diharuskan untuk bertahan hidup, namun kebutuhan dasarnya tidak tersedia, maka sudah pasti dia akan mencuri. Selaras dengan pendapat Thomas, dimana kondisi ekonomi dari negara-negara berkembang dan negara-negara miskin menghasilkan gelombang pengangguran baik bagi mereka yang memiliki keahlian maupun tidak pada tahun 1980an, dan akibatnya adalah, banyak lulusan universitas dan sekolah menengah mengikatkan diri mereka pada beragam kejahatan transnasional, termasuk perdagangan transnasional perempuan dan anak.

\section{METODE PENELITIAN}

Penelitian ini melakukan pengumpulan data dengan menggunakan Teknik kepustakaan (library research). Penulis melakukan review yang komprehensif terhadap artikel-artikel dan buku-buku yang sudah diterbitkan mengenai perdagangan orang. Untuk memulai literatur review ini, tulisan ini menetapkan beberapa parameter apa yang dimaksud dengan "perdagangan orang". Selama lebih dari satu dekade yang lalu, Perdebatan berlanjut sampai hari ini mengenai kejahatan kemanusiaan ini. Dalam tulisan ini, fokus perhatiannya ada pada klasifikasi negara asal, tujuan dan transit, penyebab, dan motif pelaku aktivitas kejahatan perdagangan orang. Tulisan ini juga menyertakan publikasi-publikasi yang mengulas aktivitas kriminal transnasional Penelitian literatur ini juga memfokuskan pada publikasi-publikasi yang berbahasa Inggris.

\section{PEMBAHASAN}

\section{Posisi Perempuan Dan Anak Dalam Perang Dan Kemiskinan}

Perang-perang di Asia, Eropa Timur, Timur Tengah, dan Amerika Selatan, termasuk juga bencana-bencana nasional yang terjadi di banyak wilayah di dunia dari tahun 1960an 
sampai tahun 1990, menciptakan banyak sekali anak-anak yatim dan piatu di Indonesia, Kamboja, India, Afrika, Timur Tengah dan sebagainya. Anak-anak yatim piatu ini masuk pada kondisi yang histeris, dan akibatnya adalah, beberapa predator anak menemukan pantipanti yatim piatu dan panti-panti lainnya untuk supplai perdagangan anak. Di Asia Tenggara, ada banyak sekali anak yatim dimana panti yang mereka tinggali tidak dapat menangani mereka sepenuhnya, khususnya yang terjadi di Thailand (Bales, 2002). beberapa dari anak yatim ini ada di jalan-jalan yang memudahkan para penjual anak dan turis-turis yang mencari kepuasan seksual. Secara illegal berpindah anak-anak yang tak memiliki rumah dari Asia Tenggara menuju ke Afrika, Amerika Serikat, dan Timur Tengah menjadi perjalanan yang mudah karena anak-anak ini tidak memiliki orang tua atau wali yang peduli terhadap ancaman perdagangan orang.

Perang dan bencana alam menciptakan kesempatan baru bagi kejahatan penyelundupan dan perdagangan orang transnasional dimana kejahatan ini memang sudah ada sebelumnya di negara-negara miskin. Di Asia Tenggara, Kamboja adalah satu dari negara berkembang di dunia, dengan pendapatan perkapita \$280 U.S Dollar per tahun. Hampir semua pekerja pabrik garmen di Kamboja adalah perempuan muda yang belum menikah dengan kisaran usia 18 dan 25 tahun. Hampir Semua perempuan ini lahir dan dibesarkan di propinsi-propinsi Thailand Utara, dimana tidak ada peluang kerja sama sekali. Para perempuan ini, menerima rata-rata $\$ 40$ per bulan, dan mereka dipaksa untuk membayar masa enam bulan percobaan sebesar $\$ 240$ untuk tetap mendapatkan pekerjaan tersebut. Mereka stress karena harus mengirimkan uang kepada orang tua mereka dan orang-orang yang mereka sayang agar terbebas dari hutang.

Akibatnya adalah, para perempuan muda ini merasa bahwa mereka harus menjadi pekerja seksual agar mendapatkan uang tambahan untuk memenuhi tuntutan orang tua dan agar dapat membayar sewa tempat tinggal dan transportasi ke tempat kerja mereka. Merasa kesepian, jam kerja yang panjang (kadang-kadang bahkan mereka harus bekerja 16 jam per hari), kondisi hidup yang memprihatinkan, nutrisi yang seadanya, dan minim pengawalan, menyebabkan banyak dari mereka yang terjebak pada turis-turis Barat yang menawarkan janji palsu mengenai kehidupan indah di Amerika Serikat, Jerman, Inggris, Kanada, Perancis, dan lain sebagainya. Banyak dari kaum wanita ini yang terjebak masuk pada lingkaran kejahatan-kejahatan kemanusian (Bales, 2002; Ehrenreich, 2002; Lan, 2002; Parrerias, 2002). 
Kondisi yang sama terjadi di wilayah Thailand Utara. Masyarakatnya hidup dalam kemiskinan dan sangat minim pendidikan. Hampir semua orang tua justru mengalami kecanduan terhadap heroin, dan akibatnya adalah anak-anak mereka harus bekerja pada usia yang sangat dini. Beberapa anak kecil ini sangat mudah untuk diculik dan ditinggalkan di daerah miskin oleh kelompok penjual orang dan kemudian dijual (Bales, 2002).

Dalam aspek eksploitasi perempuan dan anak di tenaga kerja paksa, Asia Tenggara, khususnya Thailand dan Kamboja merupakan pusatnya. Beberapa anak berusia dibawah 18 tahun dipaksa bekerja selama 16 jam di pabruk-pabrik. Di Phnom Penh, ibu kota Kamboja, yang merupakan rumah bagi industri garmen negara, 90 persen pekerjanya adalah perempuan. Perempuan-perempuan ini mendapatkan sedikit sekali upah atau bahkan tidak lagi memiliki uang setalah membayar hutang mereka. Ekspolitasi perempuan dan anak tidak hanya ditempatkan di Kamboja tentunya. Situasi yang sama dapat dilihat di Gabon dan Afrika Southwest, dimana anak-anak laki-laki dipaksa bekerja di pertanian tanpa dibayar dan mereka terikat sampai batas waktu yang tidak ditentukan.

Anak-anak ini biasanya terikat hutang yang banyak. Mereka biasanya pada akhir bulan menyetor kepada tuannya. Beberapa dari anak-anak ini ada juga yang sukarela memasuki dua negara ini tapi ketika ingin kembali ke negaranya, mereka harus dihadapkan pada biaya transportasi. Sebab lain dari perdagangan perempuan dan anak adalah globalisasi. Ide untuk berbagi kebijakan-kebijakan poliitk, budaya, perdagangan, dan kesepakatankesepakatan regional akan dieliminasi oleh permintaan akan visa untuk memasuki perbatasan, seperti, Economic Cooperation of West African States Nations, European Union/ North Atlantic Treaty Organisation Nations, North American States, dan model integrasi lainnya yang membuat perdagangan perempuan dan anak lintas batas menjadi mudah untuk dilakukan. Khususnya negara yang menjadi bagian dari kesepakatan integrasi tersebut.

Pada faktanya, pengesahkan beragam undang-undang tanpa penegakan aturan adalah jalan memperluas kriminilasasi ini. Ketika hukum dibuat untuk mengontrol prilaku namun tidak diterapkan aturannya, ini akan membuat masyarakat justru terus melakukan kejahatan tanpa ada larangan. Ini karena tidak adanya hukuman yang bisa dijadikan contoh bagi pihak lain. Para penjual anak dan perempuan paham akan sistem hukum ini, khususnya karena tidak adanya hukuman bagi mereka-mereka yang melakukan pelanggaran seks terhadap kaum perempuan. Beberapa dari penegakan hukum juga ada yang dikorupsi dalam pelakasanaannya. Akibatnya adalah, perdagangan perempuan dan anak bukanlah sebuah 
kejahatan yang harus ditakuti bagi mereka yang terlibat di dalamnya, karena lemahnya penegakan hukum sebagaimana yang seharusnya.

\section{Perempuan dan Diskriminasi}

Tingkatan perdagangan perempuan dan anak mengerikan hampir di semua wilayah, namun distuasi di Timur Tengah, khususnya Lebanon, adalah yang paling memprihatinkan. Perbudakan seks, eksploitasi tenaga kerja anak, perbudakan anak, pemerkosaan, pelanggaran terhadap hak asasi manusia terhadap para migran dan perempuan, gadis-gadis muda serta anak laki-laki di Lebanon melewati batas epidemik. Situasinya sangat buruk, sebagaimana yang dilaporkan oleh Amnesty Internasional, dimana sampai pada titik PBB mengirimkan seorang ahli perdagangan orang untuk mengunjungi Lebanon dan menginvestigasinya. Sigma Huda, Reporter khusus United Nations Commis on Human Trafficking in Persons, khususnya untuk perempuan dan anak, memberitahukan media mengenai temuannya di Beirut pada 15 September, 2005, di akhir kunjungannya. Itu adalah sembilan hari temuannya, bagian kecil yang diambil dari persentasi Huda terhadap Press di Beirut, menunjukkan tingkat perdagangan orang dan pelanggaran hak asasi manusia di Lebanon.

Dalam perjalanan misi seorang peneliti Huda ditemukan bahwa bahwa sejumlah orang, perempuan menjadi bagian yang mayoritas, menjadi korban yang diperdagangan di Lebanon. Sayangnya, mereka-mereka ini adalah warga Lebanon yang tidak dikenal, mungkin karena mereka para korban berkebangsaan asing atau berasal dari masyarakat dengan status sosial yang rendah Korban-korban perdagangan orang Lebanon seringkali mereka yang tidak terlihat karena mereka menderita di tempat-tempat yang tersembunyi dari sorot mata publik seperti rumah dan kamar-kamar hotel. Banyak dari elemen masyarakat, termasuk pegawai pemerintah mengetahui kondisi diskriminasi ini yang berbasis ras, warna kulit, etnisitas dan jender yang berkontribusi terhadap kemakmuran perdagangan orang. Budaya taboo mencegah diskusi publik mengenai isu-isu yang berhubungan dengan ekspolitasi seksual juga menjadi faktor terhadap tragedi ini (Huda, 2005).

Menurut Huda (2005), antara 150.000 sampai 200.000 para pekerja migran di Lebanon adalah korban-korban perdagangan orang. 1946 Labor Code Lebanon tidak melindungi para pekerja domestik yang berasal dari negara asing, yang mayoritasnya adalah perempuan yang datang dari Asia dan Afrika. Menurut Huda, mereka tidak punya akses untuk ke pengadilan tenaga kerja Lebanon (Lebanese Labour Courts). Huda melaporkan bahwa para migran menandatangani sebuah kontrak dengan sebuah agensi tenaga kerja di 
negara mereka, namun saat tiba di Lebanon, mereka dipaksa menandatangani kontrak kedua, " dimana kontrak tersebut dalam bahasa Arab" yang bahasanya sama sekali tidak mereka pahami.

Para migran ini dipaksa bekerja 16 jam per hari, tujuh hari dalam satu minggu, tanpa kejelasan upah mereka. Mereka tidak paham bahwa ini semua ada di kontrak baru yang mereka tandatangani. Ini adalah kontrak yang benar-benar mengerikan. Beberapa migran pernah mencoba untuk melarikan diri dari tuan-tuan mereka akan mendapatkan siksaan, pemerkosaan yang lebih mengerikan ketika mereka berhasil ditangkap (Huda, 2005). Huda juga mencatat bahwa beberapa perempuan terjebak dalam pusaran hutang dan tidak akan pernah kembali ke negara asalnya. Ketika mereka berada di Lebanon, mereka diperlakukan tidak seperti warga Lebanon.

\section{Mengidentifikasi Pelaku Perdagangan Orang}

Para pelaku perdagangan orang menyiapkan kontrak dan tanda tangan dari para perempuan mudah yang sepakat dengan tawaran yang diberikan (Richard, 2000; esadze, 2004). Mereka mengiklankan peluang-peluang kerja yang tersedia di banyak negara seperti di Eropa Barat, Amerika Serikat, Kanada, Israel, Italia, dan lain sebagainya. Sebagai tambahan, beberapa pelaku kejahatan bekerjasama dengan biro perjalanan, agensi-agensi lowongan kerja untuk merekrut para korban. Para pelaku perdagangan orang ini menyiapkan dokumendokumen perjalanan, beberapa dokumen ada yang asli, namun proses mendapatkannya justru dengan cara pemalsuan data agar mendapatkan dokumen yang dibutuhkan. Di beberapa negara asal, Perempuan dan anak yang menjadi korban penculikan diselundupkan ke Amerika Serikat, Eropa Barat, Australia atau bahkan Jepang.

Para perempuan yang diculik ini adalah mereka yang dijual dua bahkan sampai tiga kali pada pemilik rumah bordil yang berbeda. Mereka yang dengan sukarela adalah mereka yang seringkali merupakan korban dari lilitan hutang karena para penjual itu mengeksploitasi mereka dan mengharuskan para korban membayara \$10.000-50.000 dollar sebelum mereka bebas. Penculikan, ancaman, dan intimidasi dalah metode-metode rekrutmen yang digunakan di semua negara asal (Richard, 2000).

Menurut Nigerian human rights group dan Constitutional Rights Project Report banyak keluarga Nigeria yang berupaya mencari kehidupan di dalam maupun diluar Nigeria. Chukwudi Joseph yang berusia 10 tahun direkrut dan dipekerjakan di sebuah perusahaan 
kayu di Gabon. Setelah tiga tahun, pemerintah Gabon mendeportasi dirinya ke Nigeria. Dan dia tidak pernah mendapatkan upah atas kerjanya. Tope, gadis muda yang berusia 13 tahun berasala dari negara tetangganya yaitu Benin atas janji kerja, namun ketika dia sampai di Lagos (Nigeria) justru terperangkap dalam rumah bordl. Ketika dia ternyata hamil, dia justru ditinggalkan di jalanan. (Torstein, 1996). di wilayah perang seperti Rwanda, Yugoslavia, Bosnia, Kososvo, Kongo, Sudan, Sierra Leone, Liberia, Afghanista, dan Irak, para pelaku perdagangan orang tersebut menjanjikan para gadis muda, ibu, dan anak-anak mereka bahwa mereka akan dipindahkan dari wilayah perang ke tempat-tempat yang lebih baik. Mereka yang frustasi, tentu akan menerima tawaran palsu ini. Mereka justru terjebak pada perjalanan menjadi budak. Para gadis muda dan anak-anak dijual dan berkahir di prostitusi.

Penjual professional biasanya merupakan orang-orang dari sindikat kejahatan terorganisir yang memiliki teknologi untuk memproduksi paspor-paspor dari banyak negara. Bagi negara-negara maju, seperti Amerika Serikat, Jerman, Perancis, Itali, dan juga Inggris, dokumen-dokumen kejahatan terorganisir ini dapat merubah foto dari illegal migran menjadi orang yang sah untuk masuk ke Amerika Serikat, Kanada, Inggris, Perancis, Itali atau Jerman. Ini sudah terjadi sejak tahun 1970an. Dengan paspor dan visa yang asli tapi palsu, mereka dapat terbang ke negara mana saja. Kadang, kadang, para sindikat ini bahkan bekerjasama dengan kedutaan atau konsulat untuk kemudahan mendapatkan passport maupun visa.

Beberapa dari pelaku perdagangan perempuan dan anak ini adalah justru mereka yang seharusnya melindungi perempuan dan anak yakni_ polisi dan para penjaga keamanan. Beberapa polisi di negara yang berbeda dan pasukan perdamaian PBB sudah menangkap mereka-mereka yang terlibat dalam kejahatan perdagangan manusia ini. Misalnya, PBB menangkap mereka-mereka yang terlibat di Kosovo. Pada 5 Oktober 2005, didapati polisi internasional yang diduga terlibat dalam kasus perdagangan manusia, dua minggu sebelumnya, dua orang polisi lokal juga ditangkap atas kasus perdaagangan orang di Kosovo bagian Utara (Krasmigi, 2005).

Amnesty Internasional mengatakan bahwa kehadiran pasukan perdamaian internasional di Kosovo justru melancarkan eksploitasi seksual terhadap perempuan. Amnesty Internasional mengklaim bahwa PBB dan North Atlantic Treaty Organisation (NATO) di wilayah tersebut justru menggunakan perempuan dan anak yang menjadi korban 
tersebut untuk tujuan seks bagi para tentara yang terlibat dalam perdagangan perempuan dan anak. Amnesty Internasional melaporkan perlawanan terhadap perdagangan orang di Kosovo. dan mengklaim bahwa "gadis-gadis muda yang berasal dari Negara-negara Eropa Timur dijual untuk perbudakan seks".

Amnesty Internasional telah mewawancarai perempuan dan gadis-gadis muda yang telah diperdagangkan ke Maldova, Bulgaria, dan Ukraina untuk memenuhi industri seks Kosovo. Mereka melaporkan bahwa budak-budak seks dipindahkan secara illegal melewati perbatasan dan dijual di "trading houses", dimana mereka kadang-kadang dicekoki dengan narkoba dan " dirusak" sebelum dijual dari satu pedagang ke pedagang orang yang lain dengan kisaran harga dari 50 sampai dengan 3500 euro. Laporan termasuk juga bagaimana testimoni penganiayaan, penyiksaan yang dialami para perempuan tersebut, termasuk pukulan dan pemerkosaan. Laporan tersebut juga mengutuk peran pasukan perdamaian yang memperkeruh keadaan, bahkan sejak kedatangan pasukan perdamaian di tahun 1999, dimana sejumlah tempat di Kosovo dimana para perempuan dan gadis-gadis muda di eksploitasi, seperti klub malam, bar, restauran, hotel, dan cafe yang jumlahnya meningkat dari 18 di tahun 1999, menjadi 200 di tahun 2003 (Krasmigi, 2005).

\section{SIMPULAN}

Tekanan ekonomi adalah faktor utama dalam perdagangan perempuan dan anak. Baik kaum kaya maupun miskin menginginkan hal-hal baik dalam hidup. Yang kaya menginginkan untuk menjadi lebih kaya, dan kaum miskin juga tidak ingin terus menerus terperangkap dalam kemiskinan. Kedua kelompok masyarakat ini berusaha untuk mendapatkan kekayaan dengan beragam cara. Oleh karena itu, mengontrol akses beberapa orang dalam upaya pencarian kekayaan mereka adalah salah satu cara yang akhirnya ditempuh. Perdagangan perempuan dan anak adalah persoalan umum di hampir semua wilayah, dimana peluang untuk bertahan hidup memang minim, seperti yang terjadi di Thailand Utara, daerah pedesaan Kamboja, negara-negara di Eropa Timur, dan Afrika. Di wilayah-wilayah ini, kemiskinan menjadi alasan wajar bagi banyak pelakumelakukan kejahatan terhadap para gadis muda dan anak-anak. Bertahan hidup mengalahkan aspek moral dan kemanusiaan. 


\section{DAFTAR PUSTAKA}

Bales, K. (2002). Because she looks like a child. In: Global Woman: Nannies, Maids, and Sex Workers in the New Economy, ed. Barbara Ehrenreich and Arlie Russell Hochschild, Henry Holt, New York.

Beccaria, C. (1819). On Crimes and Punishment, trans. Edward D. Ingraham, 2nd ed., Philip H. Nicklin, Philadelphia.

Bentham, J. (1967). A Fragment on Government and an Introduction to the Principles of Morals and Legislation, Basil Blackwell, Oxford.

Chambliss W. dan M. Mankoff. (1976). Whose Law? What Order? A Conflict Approach to Criminology, John Wiley and Sons, New York.

Durkheim, E. (1964). Division of Labor in Society, Free Press, New York.

Ehrenreich, B. (2002). Maid to Order. In: Global Woman: Nannies, Maids, and Sex Workers in the New Economy, ed. Barbara Ehrenreich and Arlie Russell Hochschild,

Henry Holt, New York.

Hirschi, T. (1969). The Causes of Delinquency, University of California Press, Berkeley.

Huda, S.(2005). Human trafficking: Expert on trafficking in persons end visit to Lebanon, http://www.humantrafficking.org/collaboration/regional/ame/news/2005_

09/expert_statement.

Lan, P. (2002). Among women: Migrant domestics and their Taiwanese employers across generations. In: Global Woman: Nannies, Maids, and Sex Workers in the New Economy, ed. Barbara Ehrenreich and Arlie Russell Hochschild, New York: Henry Holt, New York.

Krasmigi,E. (2005). ISN Security Watch, http://www.humantrafficking.org/collaboration/ regional/seur/news/2005_09/combating.htm.

McCaghy, C. (1980).Crime in America, Free Press, New York.

Merton, R. K. (1968). Social Theory and Social Structure, Free Press, New York.

More, T. (1949). Utopia, trans. H.B.S. Ogden, Appletone-Century Crofts, New York, 1516.

Parrerias, R.S. (2002). The care crisis in the Philippines: Children and transnational families in the new global economy. In: Global Woman: Nannies, Maids, and Sex

Workers in the New Economy, ed. Barbara Ehrenreich and Arlie Russell Hoch schild, Henry Holt, New York.

Quinney, R. (1977). Class, State and Crime: On the Theory and Practice of Criminal Justice, David McKay, New York.

Richard, A.O. International Trax̉ cking in Women in the United States: A Contem porary Manifestation of Slavery and Organized Crime, Center for the Study of Intelligence, Washington, D.C., 2000.

Torstein,M. (1996). Child Slavery: Nigerian Human Rights Group Reporting, Press Digest, Lagos, Nigeria. 